\title{
Phenomenological Research Methodology
}

\author{
Neville Greening \\ Doctor of Philosophy Academic Mixed Research Methods \\ Osaka University-8-1-1 Aomatani-higashi, Minoh, \\ OSAKA 562-8558 JAPAN \\ Email: Osaka.university2017@gmail.com \\ DOI: $10.31364 / \mathrm{SCIRJ} / \mathrm{v} 7 . \mathrm{i} 5.2019 . P 0519656$ \\ http://dx.doi.org/10.31364/SCIRJ/v7.i5.2019.P0519656
}

\begin{abstract}
The phenomenological research methodology relates to several approaches that in turn, they are applied to single cases or to the deliberate samples that are carefully chosen. Like individual studies, it is easier to identify issues that show discrepancies, failures, favorable inferences, and attention to distinct situations while conducting management research (Groenewald, 2004 pg. 87). Clark Moustak as theoretical underpinnings of phenomenology guide the reader through the process of how to manage a phenomenological study step-by-step. And so, this provides more in-depth insights on the successful phenomenological studies from distinct contexts, including the field of healthcare, therapy, psychology, victimology, as well as investigations involving gender. While conducting a phenomenological research methodology, it often pertains the four necessary steps of Bracketing, Intuiting, Analyzing and Describing. This paper looks at Phenomenological Research Methodology Applied in a Nursing Context.
\end{abstract}

Keywords: Phenomenological Research Methodology, Bracketing, Intuiting, Analyzing, Describing

\subsection{Introduction}

Clark Moustakas focuses on the theoretical underpinnings of phenomenology, in references to other scholar's elucidations, including Husserl and others. Moustakas guides the reader through the process of how to conduct a phenomenological study step-by-step. And so, this provides more in-depth insights on the successful phenomenological studies from distinct contexts, including the field of healthcare, therapy, psychology, victimology, as well as investigations involving gender. As well, his assertions are the inclusion of letters and other tools of research that are used in designing and conducting studies. More precisely is the fact that according to his elaborations, phenomenological analysis connects with different qualitative approaches that include ethnography, symbolic interactionism, and hermeneutics (Glaser, 2017 pg. 69). From this simple phenomenological articulation, his research seeks to provide a description rather than explanation through starting from a free perspective where hypotheses and preconception phenomenological research methods are effective in bringing forward the individual's perceptions and experiences at very manipulative and challenging structural assumptions (Moustakas 1994 pg. 12). For that case, through an interpretive dimension to this phenomenological study, this article aims to examine the role of phenomenological research methodology in management research, the steps involved in phenomenological research method, and my understanding of phenomenological research methodology by applying it to a chosen management topic - in a nursing context. 


\subsection{Phenological research Methodology}

The phenomenological research methodology is associated with some approaches that, in turn, are applied to single cases or to the deliberate samples that are selected. With such individual studies, it is easier to identify issues that show discrepancies, failures, favorable inferences, and attention to distinct situations while conducting management research (Groenewald 2004, pg. 87). On the contrary, in research that involves multiple participants, it is easier to note the strength of inferences that are heightened by the rapidly occurring actors with more than one participant. Consequently, it becomes increasingly easier to distinguish between qualitative and statistical validity when phenomenological research methodology is used (Smith, 2015 pg. 121). Also, this research methodology is significant in indicating the presence of factors and their implications in distinct contexts of cases, but; it only applies in situations where the experimental approach has been used in suggesting the extent to which the population from which the participants or examples were drawn. What's essential with phenomenological research methodology, it is easier to provide detailed comments on the situations of individuals that otherwise do not lend themselves to direct generalization, just the same way the survey research is conducted (Schutz, 1970 pg. 81).

\subsection{General Theories}

However, for the cases where validity is significant, there is need to develop general theories that will back this research methodology, in turn, provide the readers with the ability to work through their findings to the methods and investigate how the researcher has managed to develop some critical interpretations (Sanders, 1982 pg. 45; Moustakas, 1994 pg. 5). As if that is not enough, while using phenomenological research methodology in management research, the researcher may not appear in person, even though this is rare in public-domain reports. Finally, the phenomenological research method is good at surfacing deep concerns and providing the platform where the voice is heard. Unfortunately, this is less favorable and not always comfortable with some participants like funders and other clients, in specific, the situations where the researcher exposes challenges and assumptions that are taken for granted (Hycner, 1985 pg. 187). Irrespectively, many organizations perceive this facet of exposing the assumptions that are taken for granted as a key to bringing in terms the prompting action or even as a challenge to complacency (Moustakas 1994 pg. 12).

\subsection{Four Essential Steps}

While conducting a phenomenological research methodology, it often pertains the four necessary steps of:

1) Bracketing - this is the process where preconceived beliefs and opinions concerning the phenomenon research are identified and held in abeyance. In this process, as Sanders (1982 pg. 33) attempts to ascertain, the researcher brackets out the surrounding and any presuppositions contained in a bid to confront the data in a very pure form. This is regarded as the 
central component of phenomenological reduction where the isolation of genuine phenomenon is done regarding what is already established of the event.

2) Intuiting - after bracketing out is done, intuition follows, where the researcher now remains focused on the attributed meaning of the phenomenon by the preceded research. Through this process, a shared understanding of a phenomenon on whatever being studied is achieved. To efficiently accomplish this process, the researcher should provide the variance of the data until a common understanding is met. Therefore, this process calls for the researcher to be immersed in the study and the phenomenon being studied.

3) Analyzing - after accomplishing the intuition process, the analysis is the next step. In this process, coding is done where categorizing and making sense of the significant meanings of the phenomenon is created. Polkinghorne (1989 pg. 69); and Moustakas (1994 pg. 118) stresses that persistent working with the detailed data results to the emergence of essences and universal themes. When the researcher is in this process, there is the need to immerse for as long as possible for attaining pure and thorough description of the phenomenon.

4) Describing - the critical step of any phenomenological research methodology is the description. In the descriptive stage, this is where comprehension and definition of the phenomenon are done by the researcher. This is purposed to provide the final step that catapults communication and offers distinctions and critical descriptions in both written and verbal form.

\subsection{Phenomenological Research Applied in a Nursing Context}

One of the management issues where phenomenological research methodology can be applied is in a nursing background. Nevertheless, while many caregivers may be on the verge to relate to the phenomenological approach since, they see it as value sharing of nurses, it might be necessary but not sufficient on its own (Oiler, 1982 pg. 167). By using the examples by Clark Moustakas, nurses use phenomenological research methodology for many purposes (Moustakas 1994 pg. 79). Of paramount, this method gives support for the re-examination of the experiences that are taken for granted while offering caring services. This goes as far as examining the qualities of the knowledge that allows the nurses to identify its essence. And so, the goal of this methodology in the nursing context emerges to be a framework where a person's lived experiences are accurately described regarding the phenomenon being studied. Gorden (1975 pg. 115) States that for any nurse to relate to the phenomenological research methodology, it aids in valuing the experiences of individuals by making them feel like they have already gained the required skills, like interviewing. What they ought to comprehend is that even with skills of interviewing, this may not be a suitable method only. Reports by Jasper (1994, pg. 67) asserts that there is an increased number of nurses who have been drawn to phenomenology. Perhaps, the fact that in nursing, it's possible to consider experiences of a whole person, thus delivers a comprehension to patients by being perceptive and synthesizing 
with them, provide an outlet to the precarious acumen. It aids an individual in exercising control over their healthcare. What's more, using this methodology provides the nurses with respect for people, through listening and believing them. In this case, nurses can now relate the methods being used to deliver care with the information given to obtain necessary data. Quality listening skills in nurses is a notion that enables the correct creation of a good rapport in a short period.

All these and many others are dependable skills in nursing, where it's enough to allow them to carry out the proper interview in the type of research that interests them.

\subsection{Conclusion}

The very most significant phenomenological approaches are the descriptive and interpretative phenomenological approach (Lopez \& Willis, 2004, pg. 98). On the one hand, using a descriptive phenomenological approach by nurses make them believe that it is impossible to read the mind of their clients in an entirely and emphatic manner. Balls (2008, pg. 131) emphasizes that using this approach is better than using your own experiences as a nurse to interpret those of others. Also, a nurse using this method in conducting research, one would be expecting to see some bracketing out their preconceptions and ensure that there is a neutral approach to their topic of interest. Somewhat, this may mean even there is no need for conducting a literature search before any research is being carried out as a way of avoiding interviews contamination (Annells, 2007 pg. 57).

On the other hand, nurses who use the interpretative phenomenological approach are needed to indicate how their choice of research topic, research questions, and interpretations have been shaped by their own experiences. Therefore, many are expected to write the appendix to the open work. It would be inherently wrong for nurses to assume that using phenomenological research methodology is an easy option or an indication of having the necessary skills for nursing. There is a need to understand the distinct approaches in phenomenology for nurses to direct and provide information on the research process at every stage of their profession (Husserl, 2002 pg. 35).

Conflicts of Interest: The author declares no conflicts of interest regarding the publication of this paper

\section{REFERENCES}

[1] Annells, M., 2007. Guest editorial: What's common with qualitative nursing research these days? Journal of Clinical Nursing, 16(2), pp.223-224.

[2] Balls, P., 2008. Phenomenology in nursing research: methodology, interviewing, and transcribing. Nursing times, 105(32-33), pp.30-33.

[3] Glaser, B., 2017. Discovery of grounded theory: Strategies for qualitative research. Routledge. www.scirj.org 
[4] Gorden, R.L., 1975. Interviewing: Strategy, techniques, and tactics. “The” Dorsey Press.

[5] Groenewald, T., 2004. A phenomenological research design illustrated — international journal of qualitative methods, 3(1), pp.42-55.

[6] Husserl, E., 2002. The shorter logical investigations. Routledge.

Hycner, R.H., 1985. Some guidelines for the phenomenological analysis of the interview data. Human studies, 8(3), pp.279-303. [7] Jasper, M.A., 1994. Issues in phenomenology for researchers of nursing. Journal of advanced nursing, 19(2), pp.309-314.

[8] Lopez, K.A., and Willis, D.G., 2004. Descriptive versus interpretive phenomenology: Their contributions to nursing knowledge. Qualitative health research, 14(5), pp.726-735.

[9] Moustakas, C., 1994. Phenomenological research methods. Sage.

[10]. Oiler, C., 1982. The phenomenological approach in nursing research. Nursing Research, 31(3), pp.178-181.

[11] Polkinghorne, D.E., 1989. Phenomenological research methods. Existential-phenomenological perspectives in psychology: Exploring the breadth of human experience, pp.41-60.

[12]. Sanders, P., 1982. Phenomenology: A new way of viewing organizational research. Academy of management review, 7(3), pp.353-360.

[13]. Sanders, P., 1982. Phenomenology: A new way of viewing organizational research. Academy of management review, 7(3), pp.353-360.

[14]. Schutz, A., 1970. Ed HR Wagner on phenomenology and social relations Chicago.

[15] Smith, J.A. ed., 2015. Qualitative psychology: A practical guide to research methods. Sage.

Www.scirj.org

(C) 2019, Scientific Research Journal

http://dx.doi.org/10.31364/SCIRJ/v7.i5.2019.P0519XX 